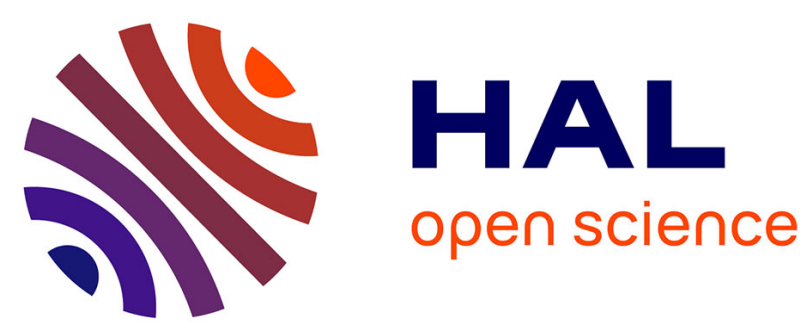

\title{
Ex situ mineral carbonation for CO2 mitigation: Evaluation of mining waste resources, aqueous carbonation processability and life cycle assessment (Carmex project)
}

Françoise Bodénan, Florent Bourgeois, Charlotte Petiot, Thierry Augé, Benjamin Bonfils, Carine Julcour-Lebigue, François Guyot, Aïssa Boukary, Joachim Tremosa, Arnault Lassin, et al.

\section{- To cite this version:}

Françoise Bodénan, Florent Bourgeois, Charlotte Petiot, Thierry Augé, Benjamin Bonfils, et al.. Ex situ mineral carbonation for $\mathrm{CO} 2$ mitigation: Evaluation of mining waste resources, aqueous carbonation processability and life cycle assessment (Carmex project). Minerals Engineering, 2014, 59, pp.52-63. 10.1016/j.mineng.2014.01.011 . hal-00987658

\section{HAL Id: hal-00987658 \\ https://hal-brgm.archives-ouvertes.fr/hal-00987658}

Submitted on 12 May 2014

HAL is a multi-disciplinary open access archive for the deposit and dissemination of scientific research documents, whether they are published or not. The documents may come from teaching and research institutions in France or abroad, or from public or private research centers.
L'archive ouverte pluridisciplinaire HAL, est destinée au dépôt et à la diffusion de documents scientifiques de niveau recherche, publiés ou non, émanant des établissements d'enseignement et de recherche français ou étrangers, des laboratoires publics ou privés. 


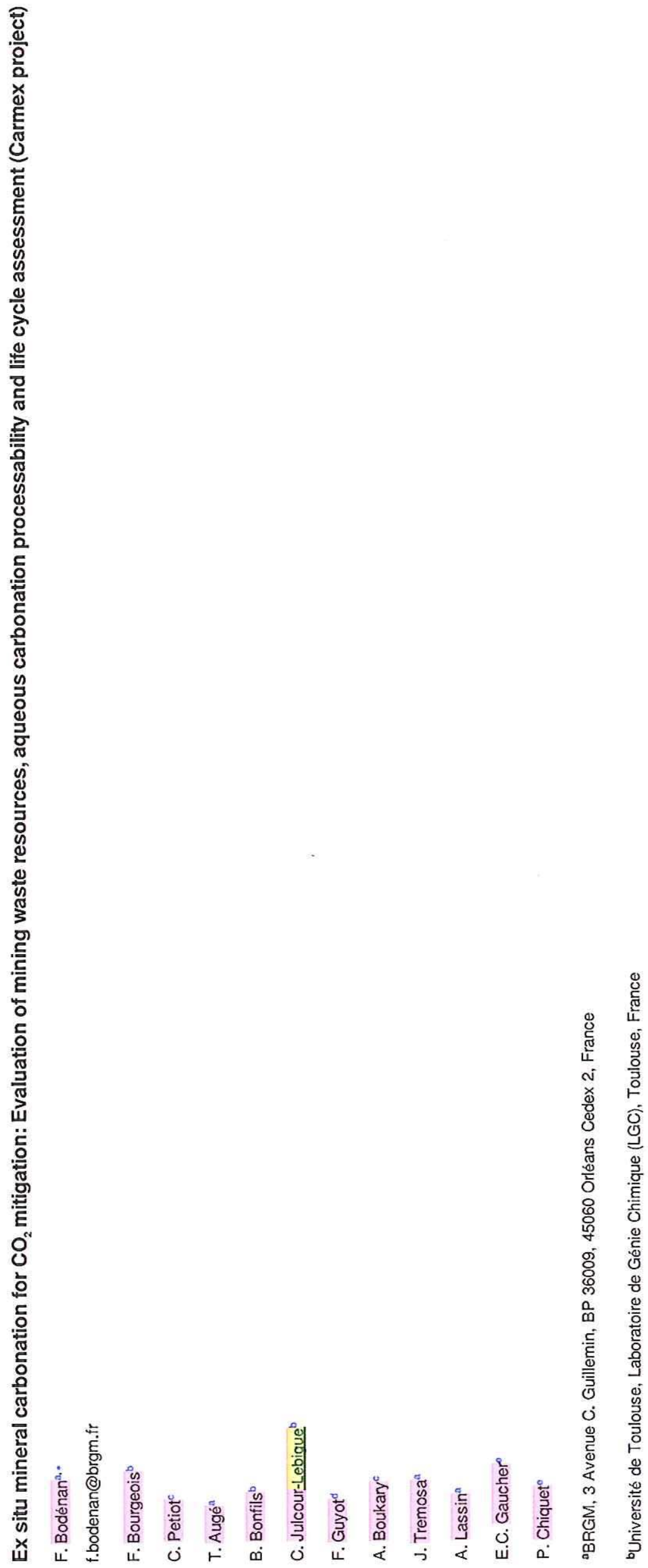

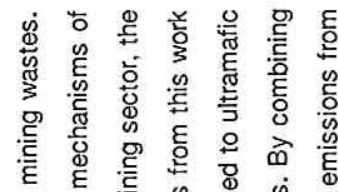

恼

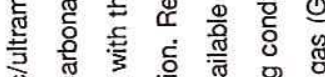

离 语

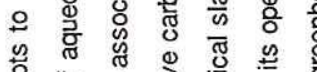

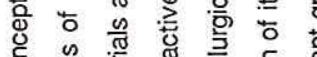

ᄃำ

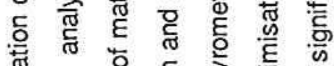

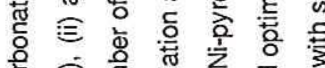

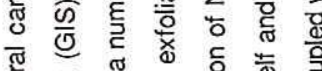

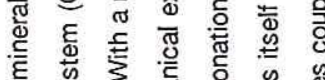

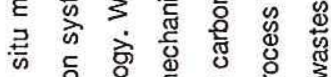

× 읋 융 है

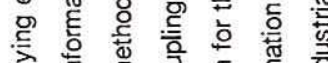

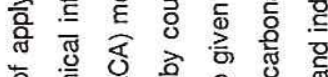

西

营

\% 용 \&

要

둘 के

ช

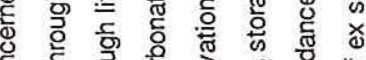

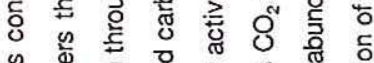

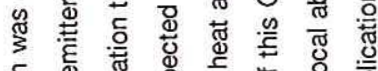

告

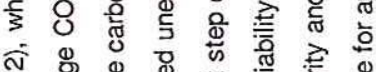

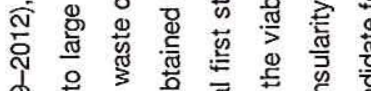

용

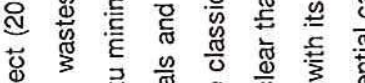

舟

×

总

希边

言

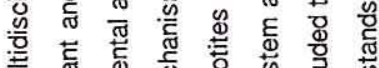

奇

ह

章 兽

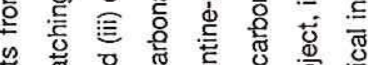

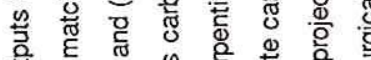

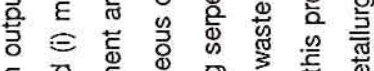

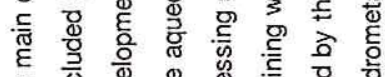

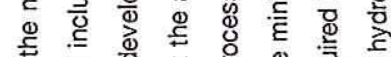

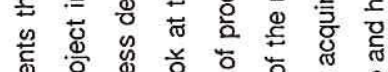

苋

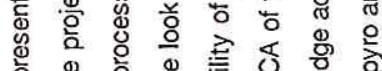

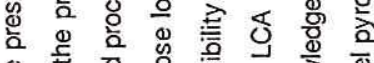

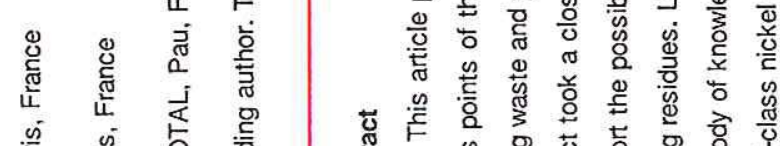

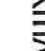

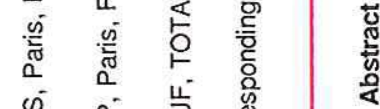

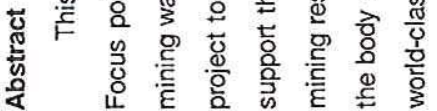




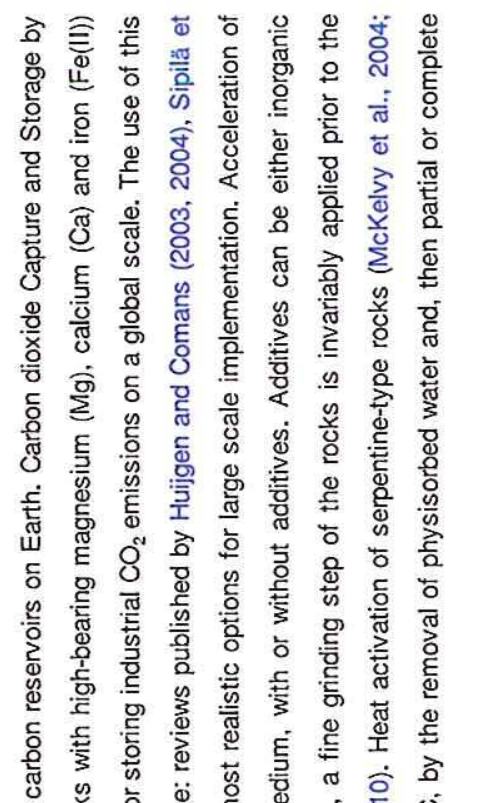

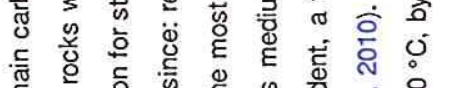

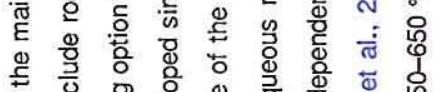

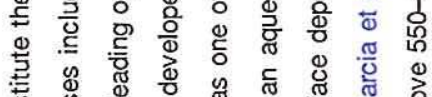

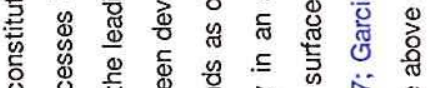

范

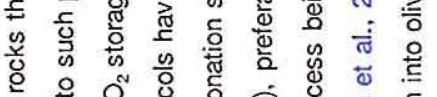

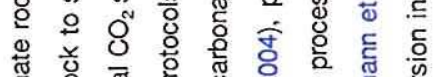

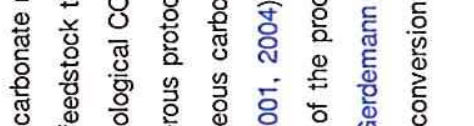

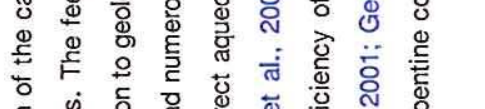

告

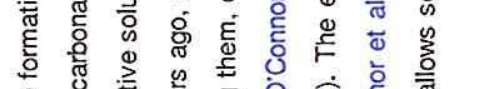

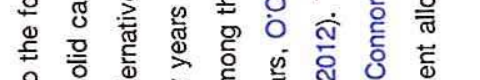

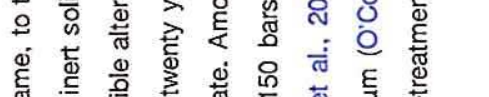

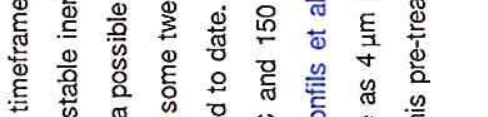

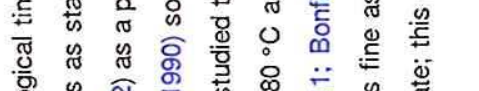

응

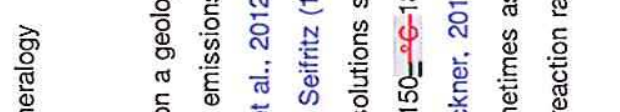

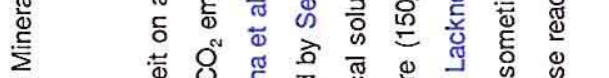

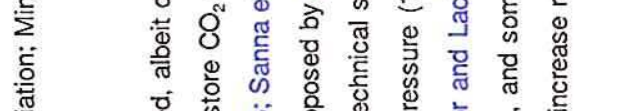

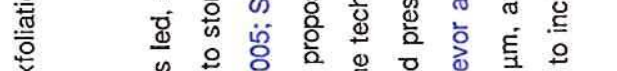

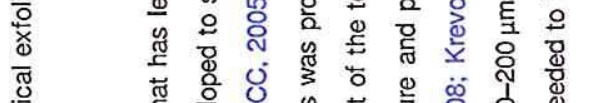

焉

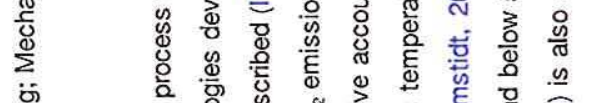

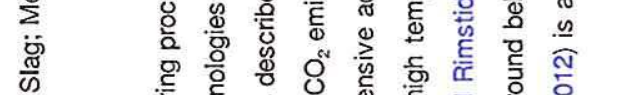

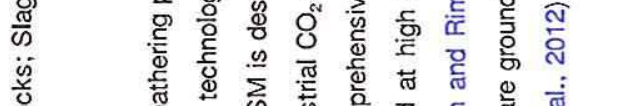

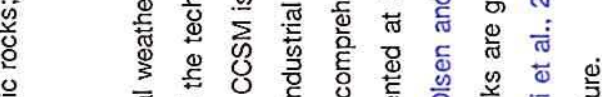

S

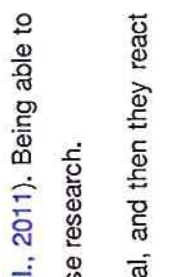

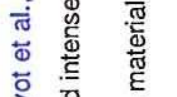

今े छ

芦䓂

त

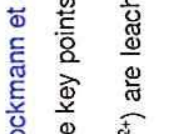

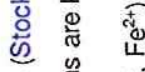

恣

高 竞

敢

둥유.

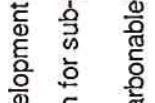

离

๖

总要蒂

总 离 苍

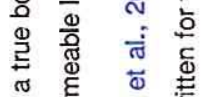

药

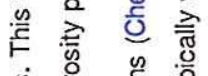

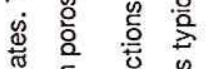

兽

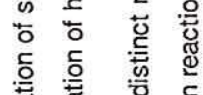

究

垫

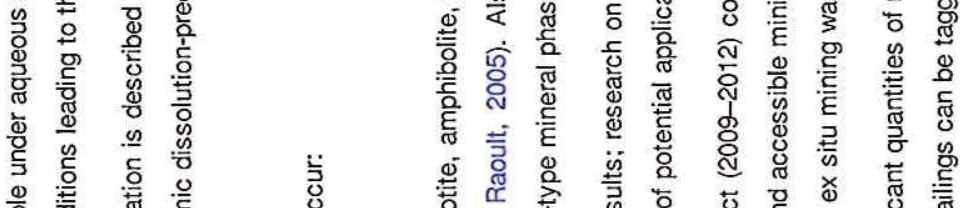

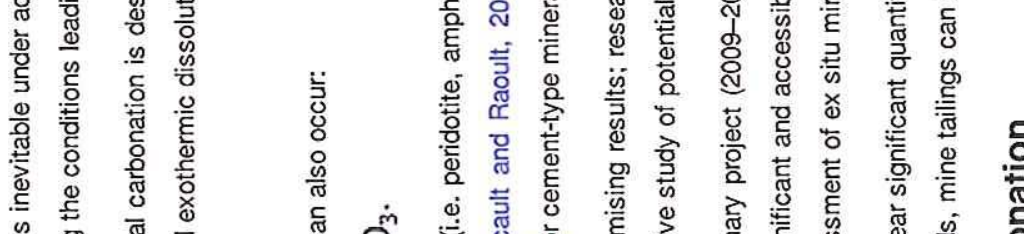

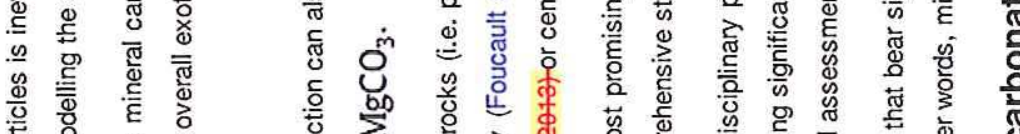

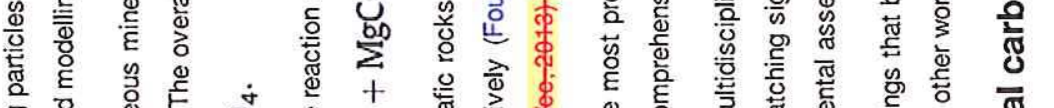

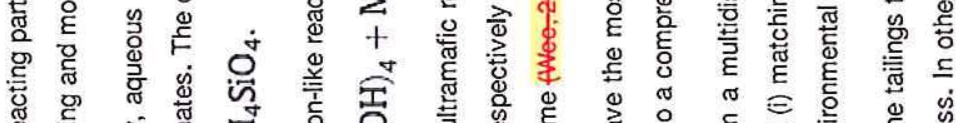

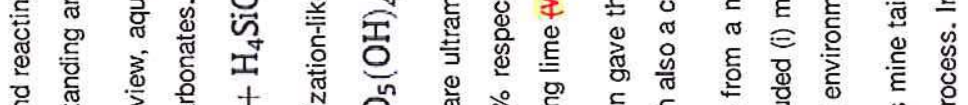

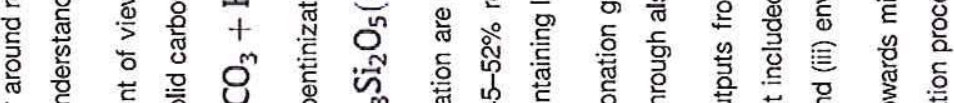

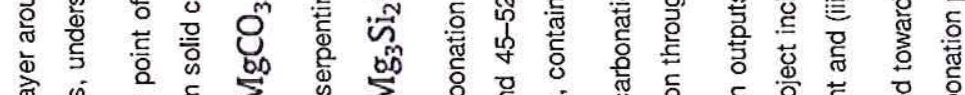

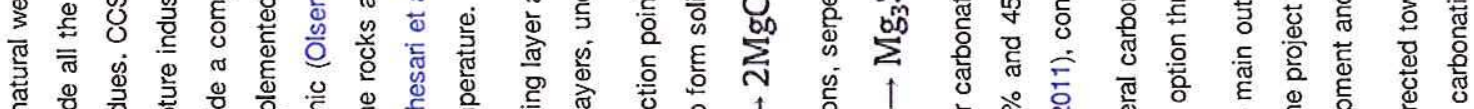

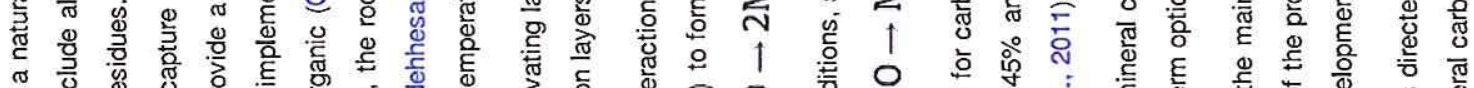
。

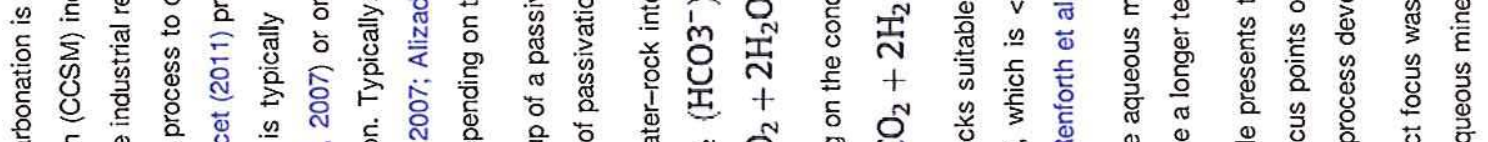

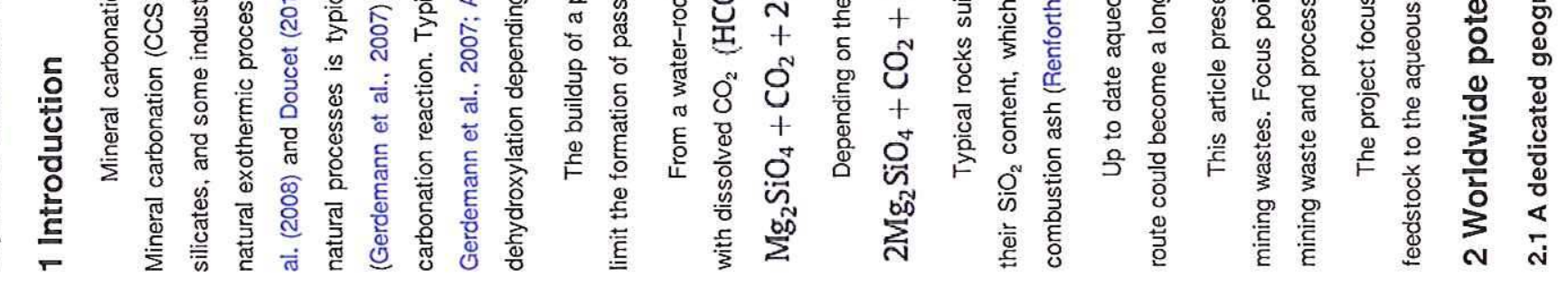




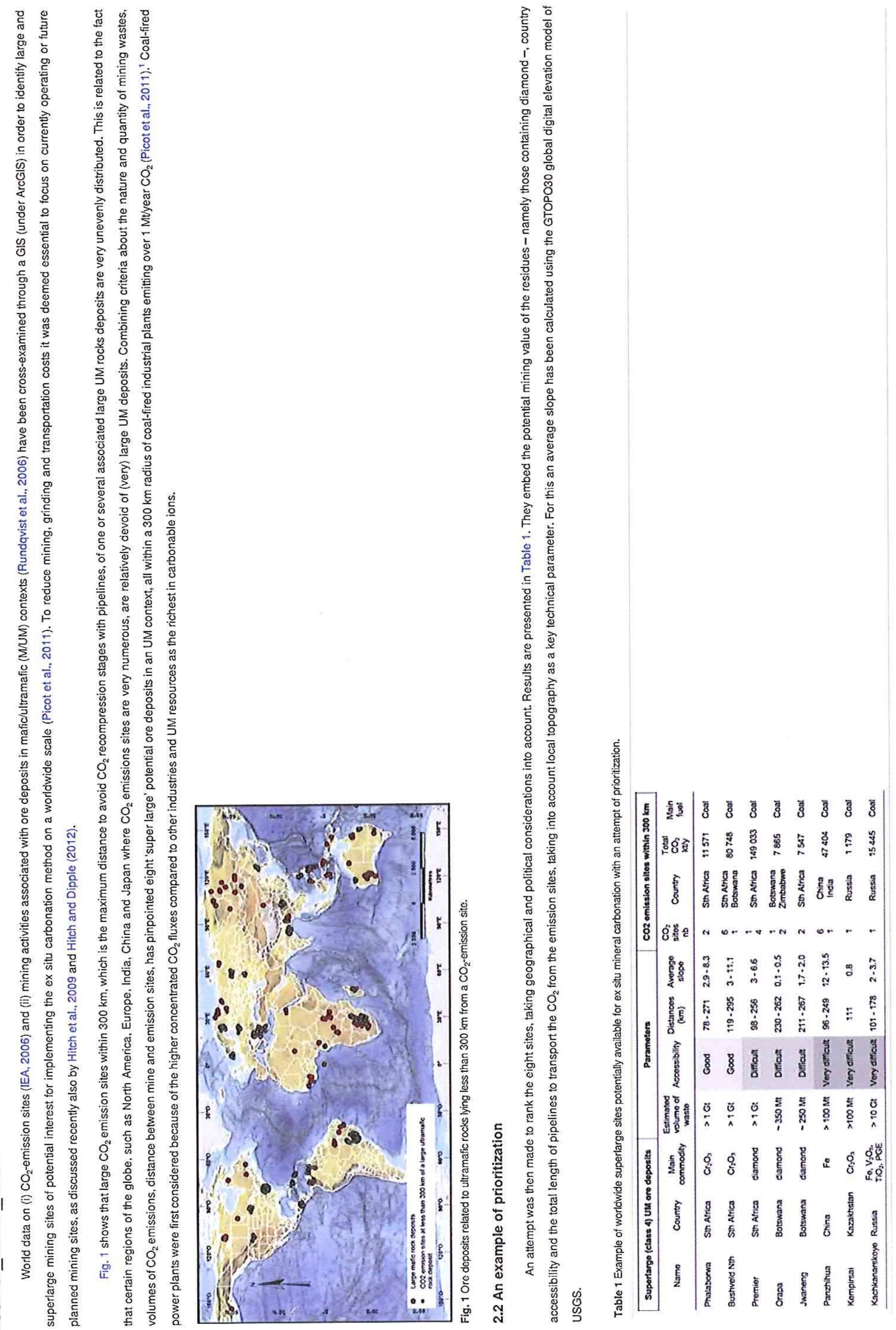




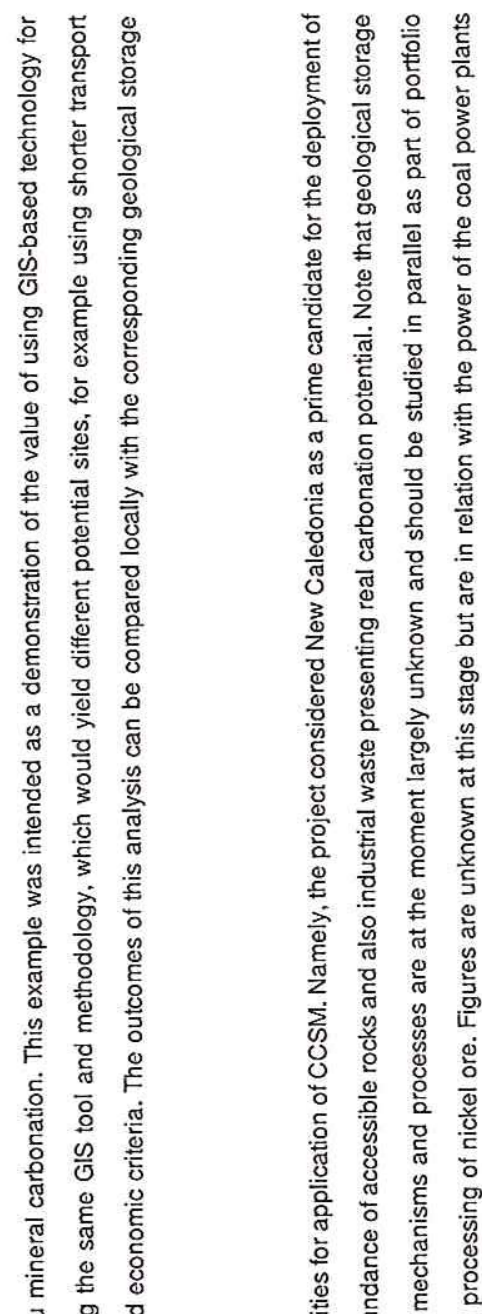

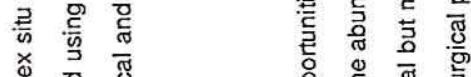

×

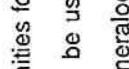

空

응 응

줗

कू

ॠ

응

迹

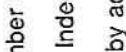

है

है

空 :

일

空

х 응

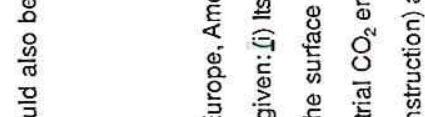

당

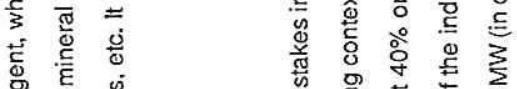

兵

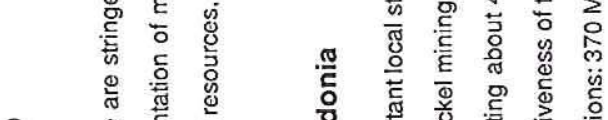

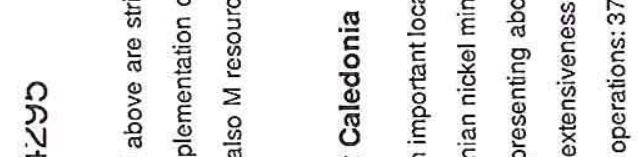

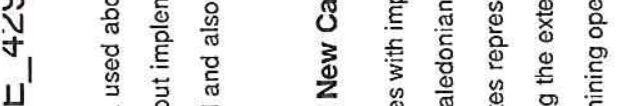

$\stackrel{4}{2}$

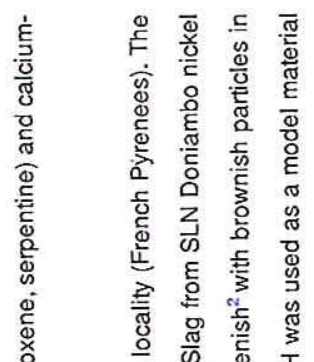

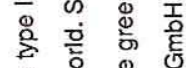

年

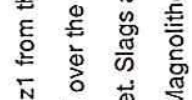

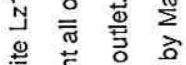

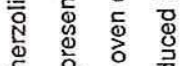

긍 을 홍

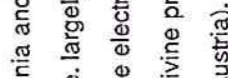

응

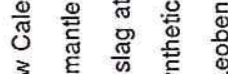

उ 3 ह

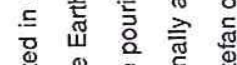

\%

立

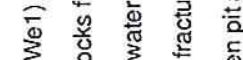

웡 ฮ

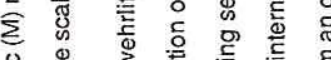

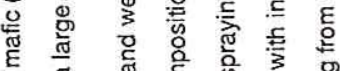

每

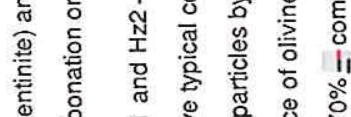

产

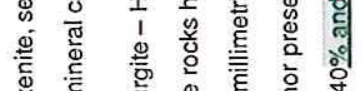

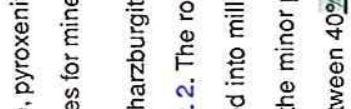

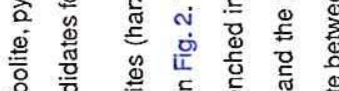

势

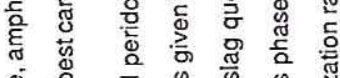

产

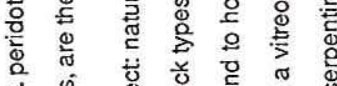

它

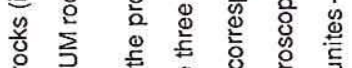

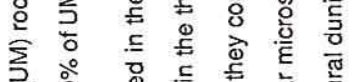

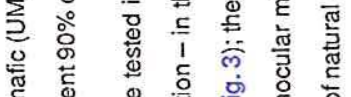
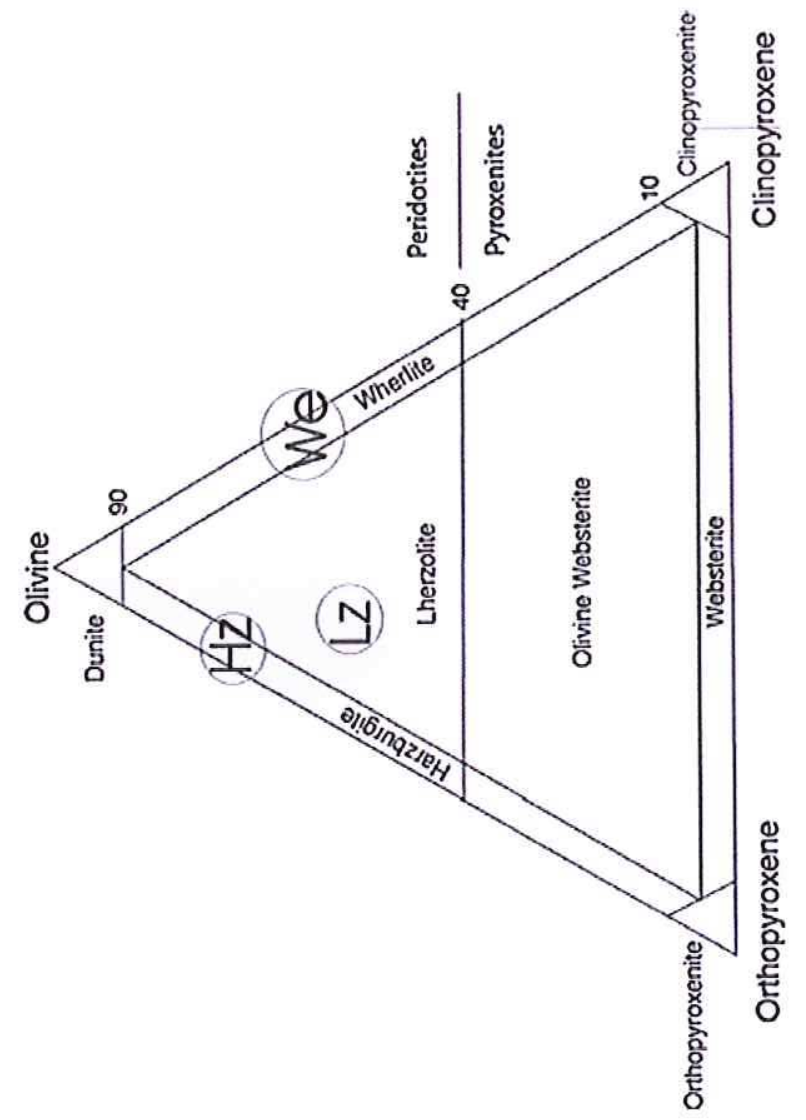


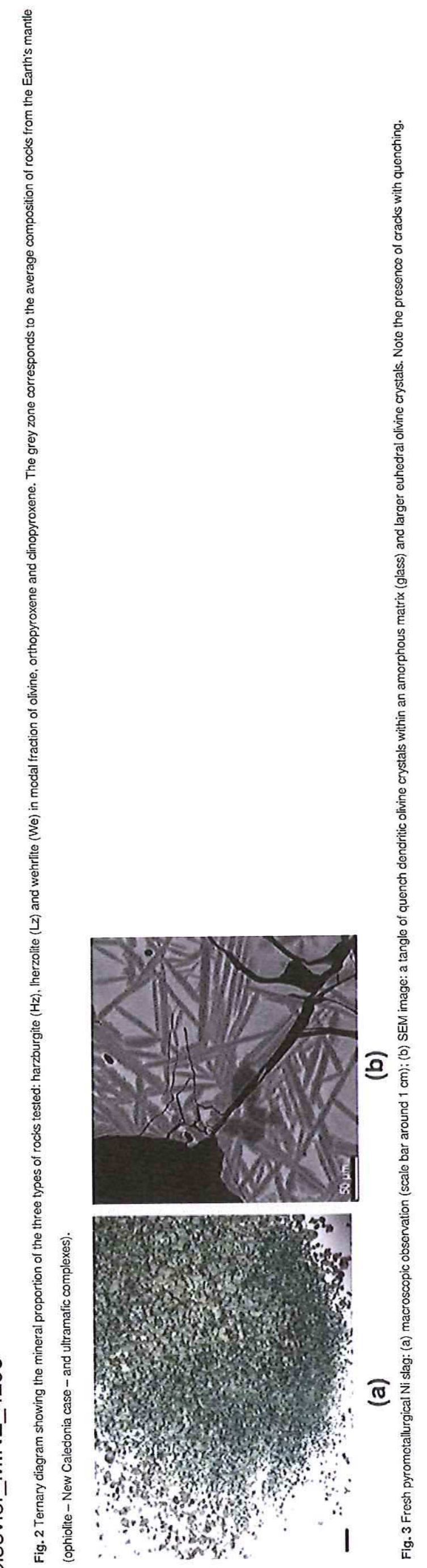

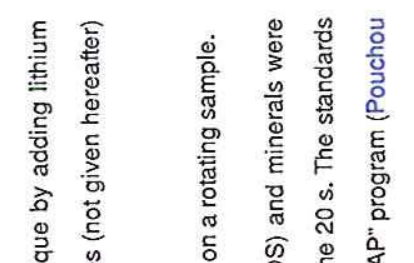

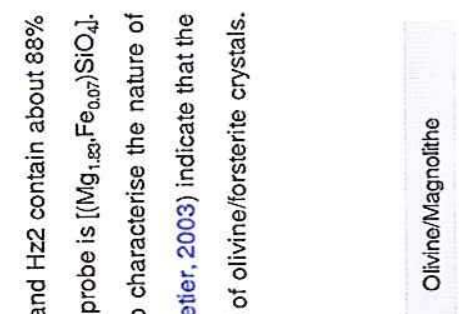

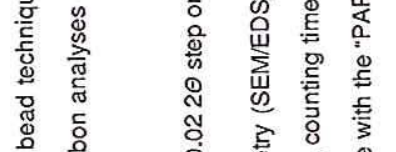

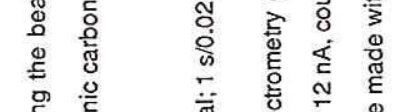

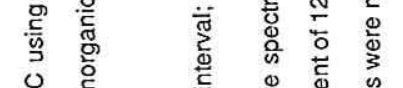

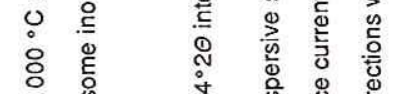

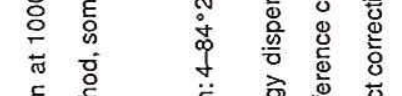

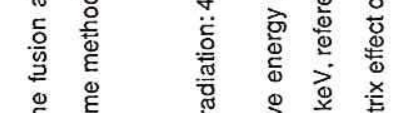

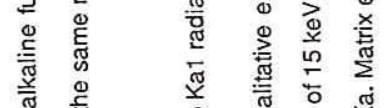

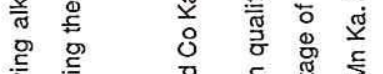

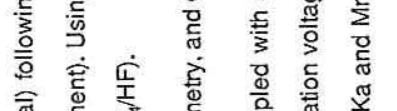

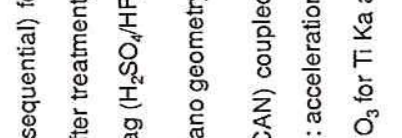

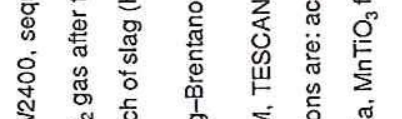

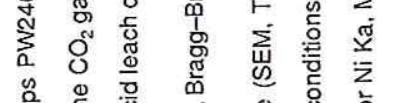

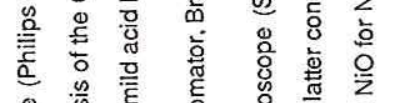

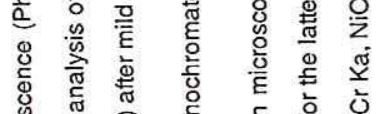

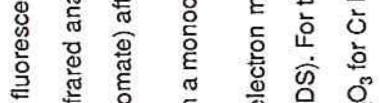

党离

京

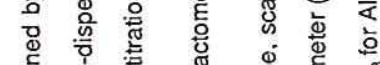

है

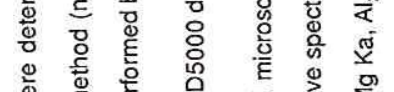

苛

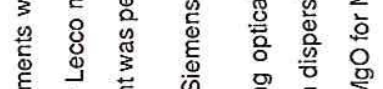

总

离

邑 离

고

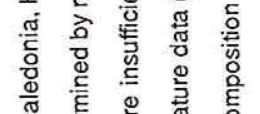

उ

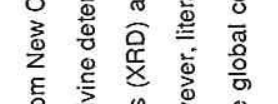

帝

का

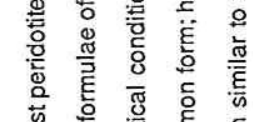

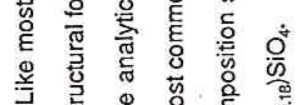

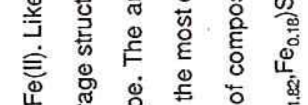

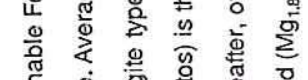

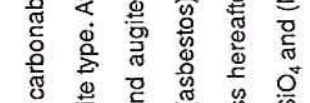

敢

胥

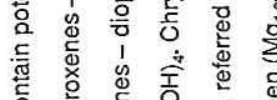

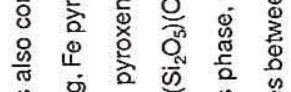

कू

宂

惫

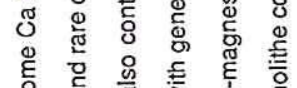

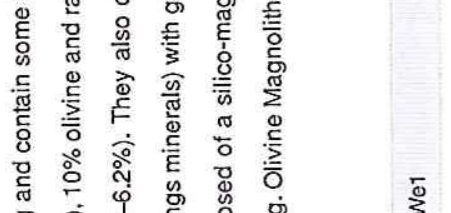

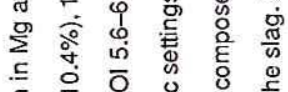

드 웅 일

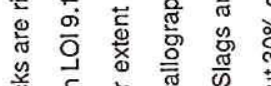

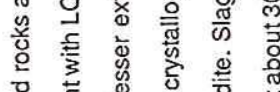

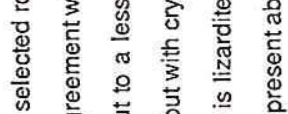

出

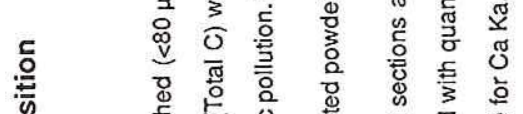

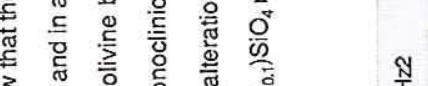

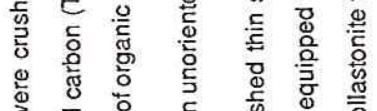

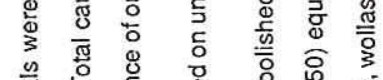

उ.

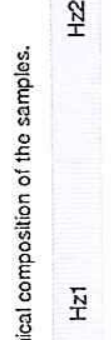

है

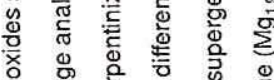

Oे

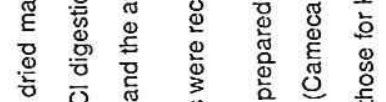

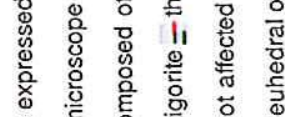

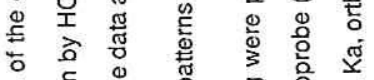

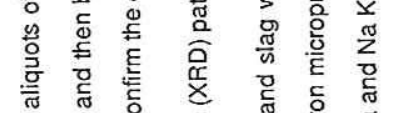

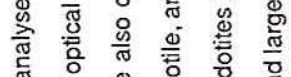

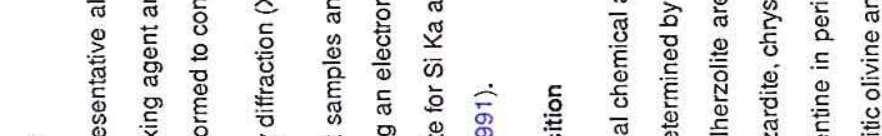




\section{त्र}

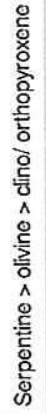

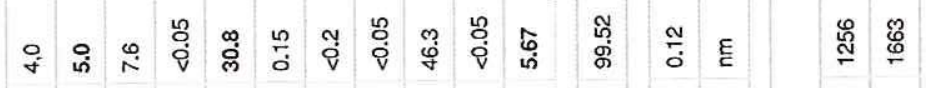




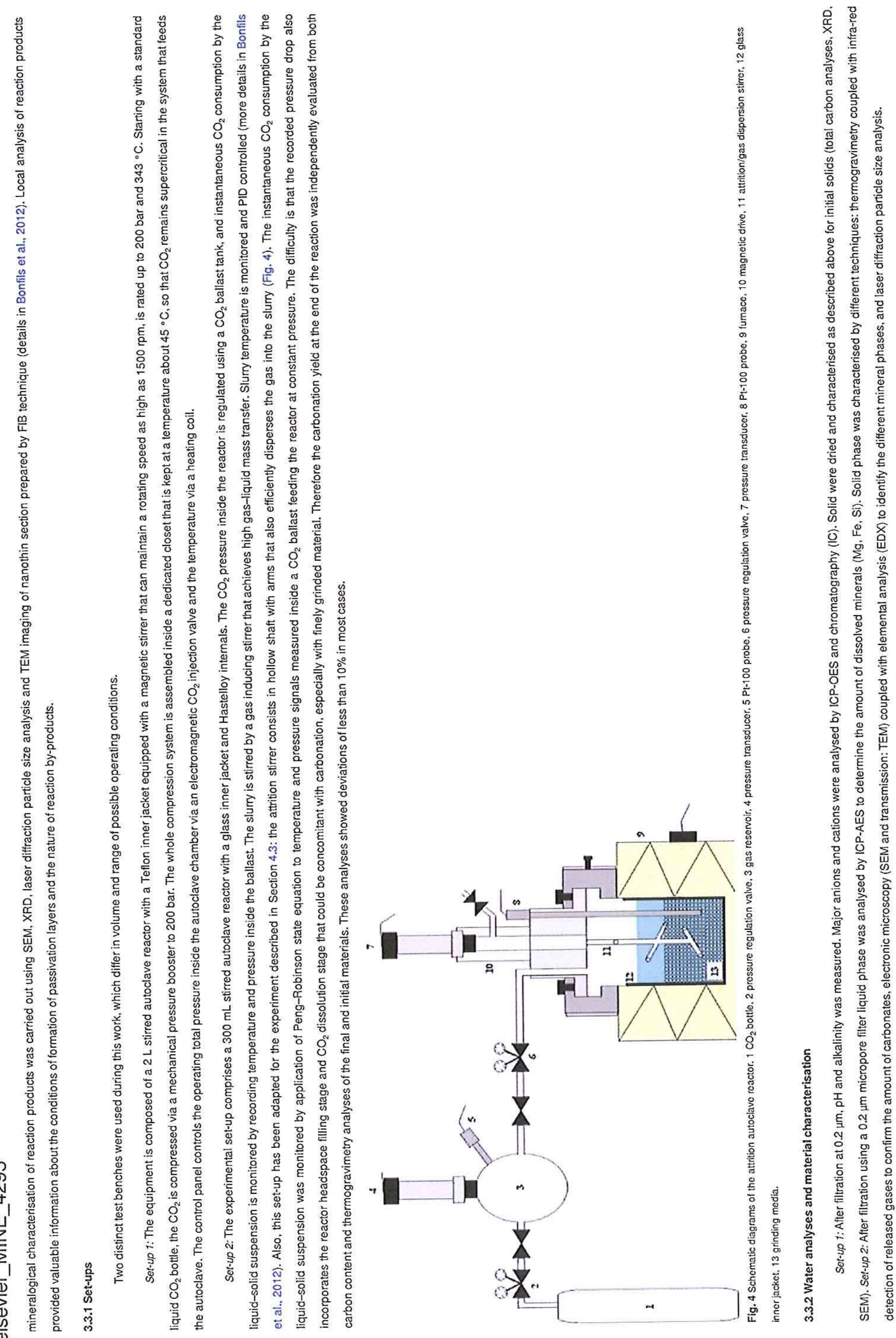




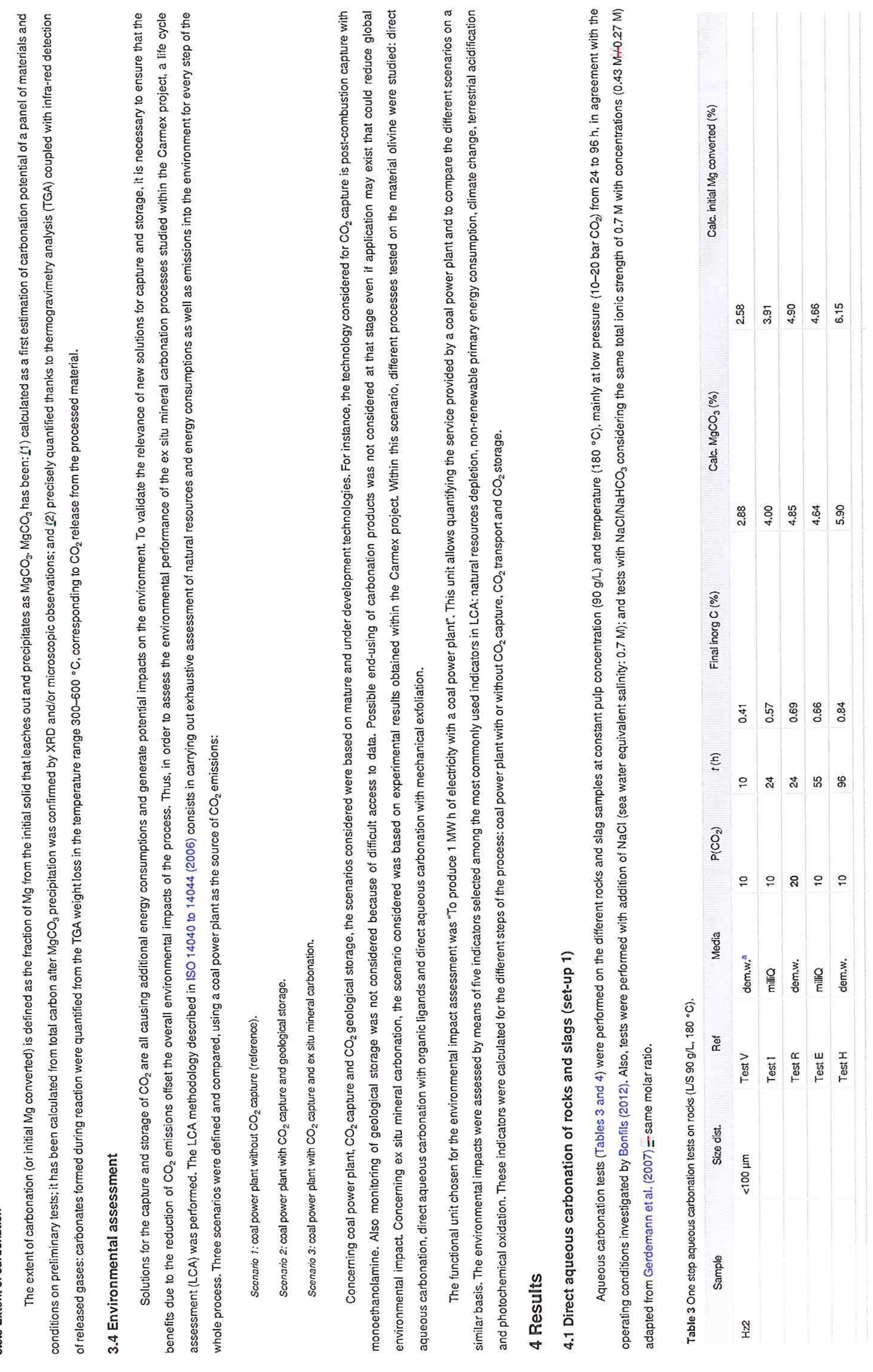




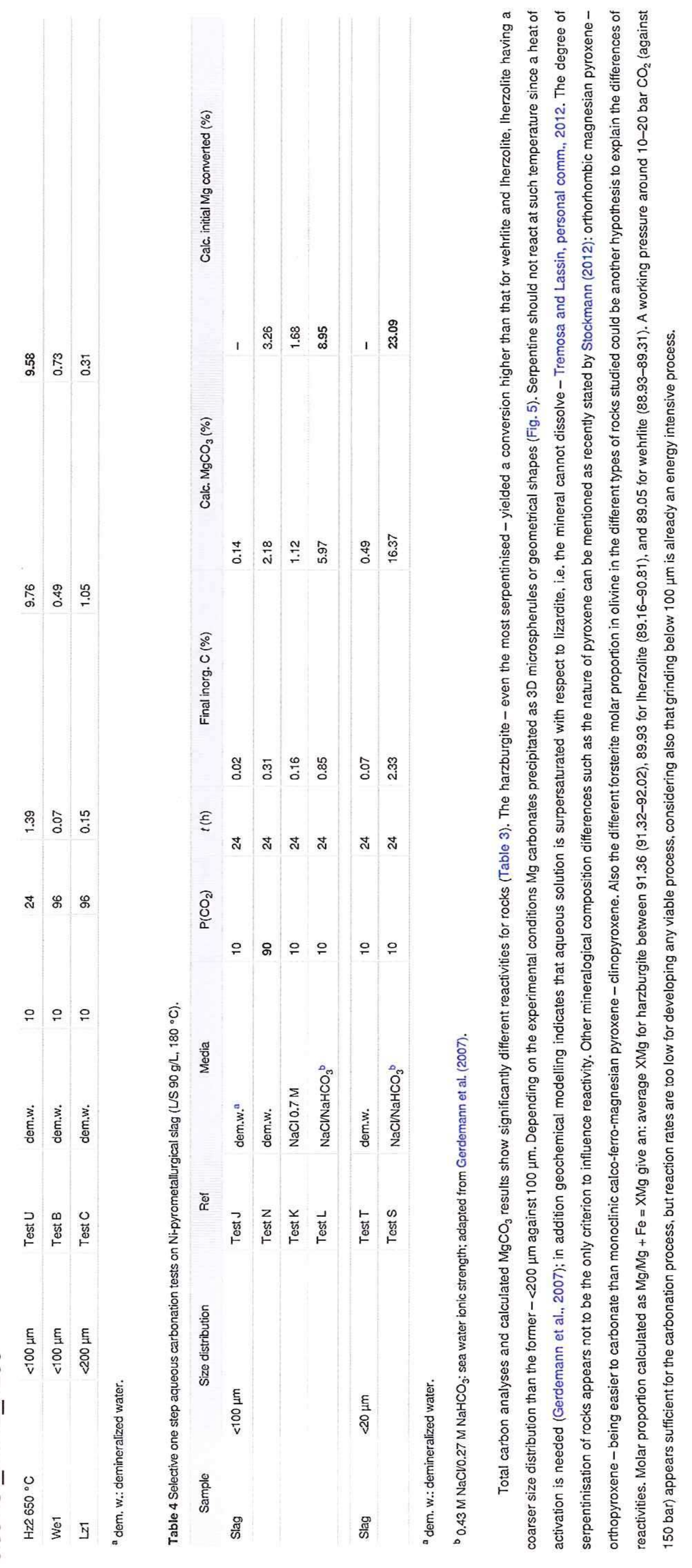




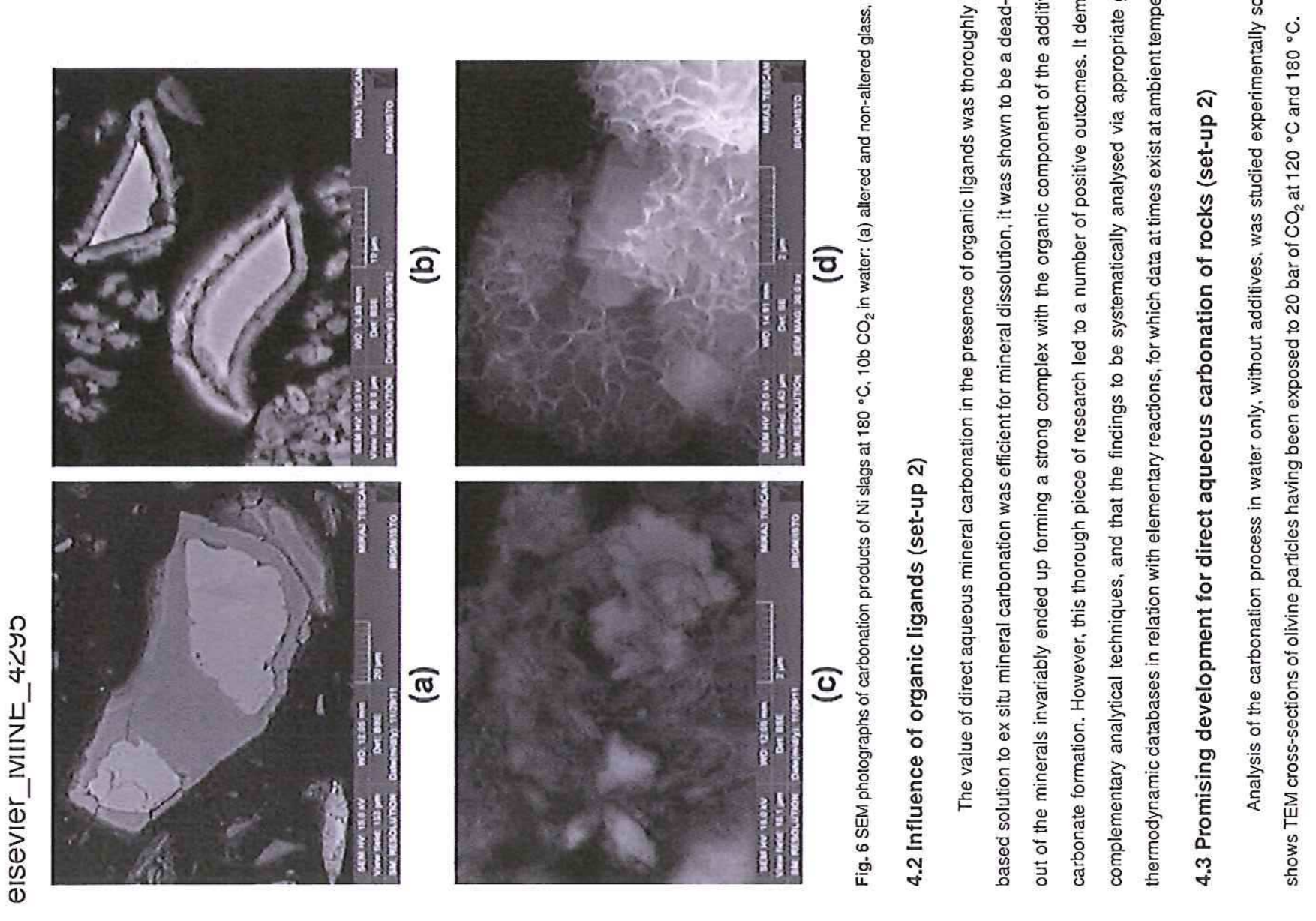




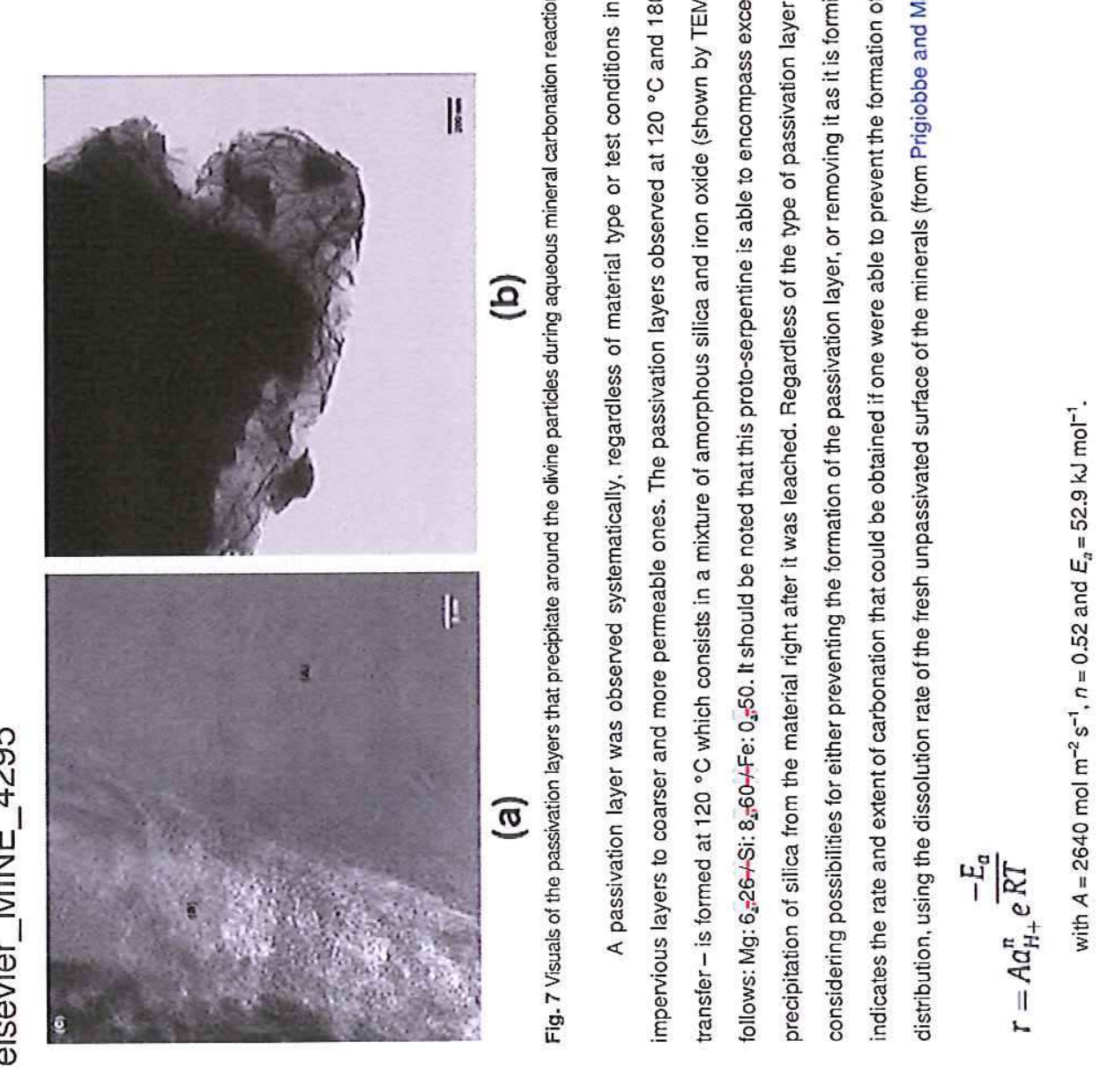




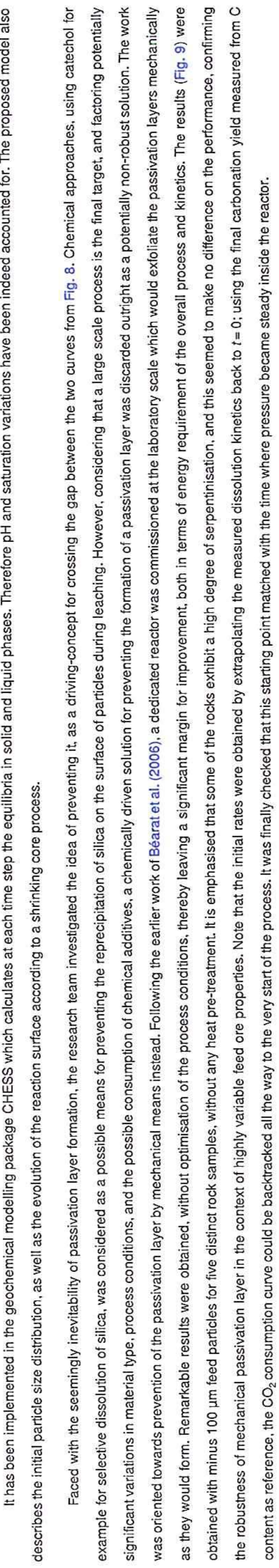





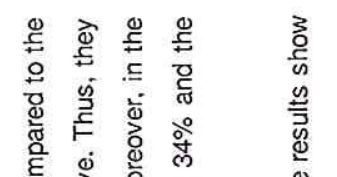

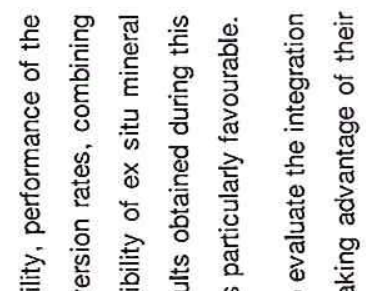

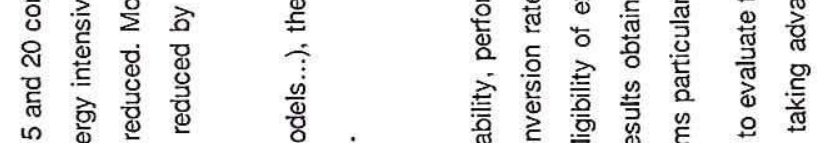

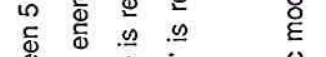

离产言高

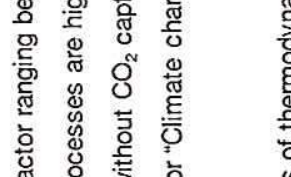

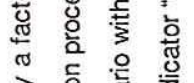

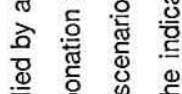

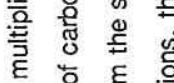

安

\%을

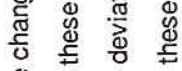

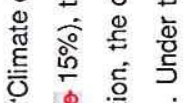

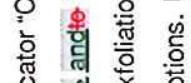

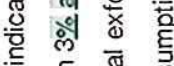

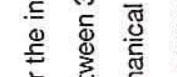

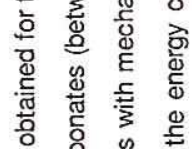

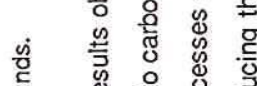

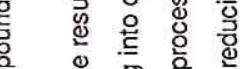

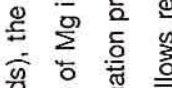

商亳

瓷

政旁

峷

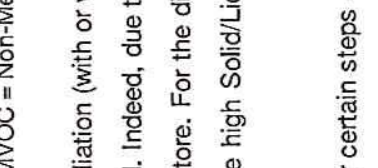

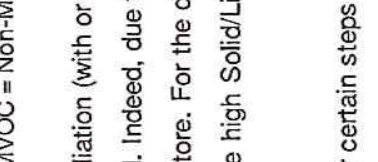

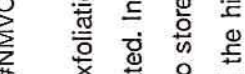

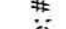

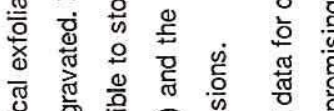

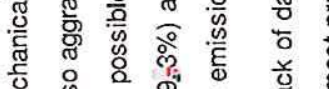

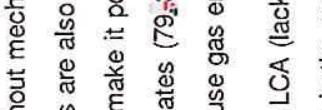

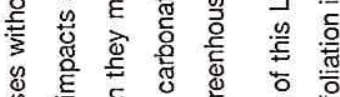

岁

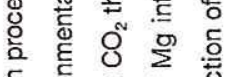

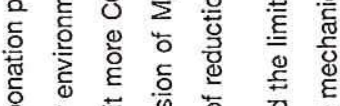

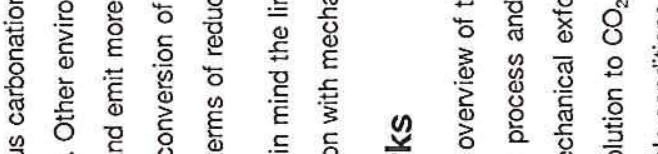

गु.

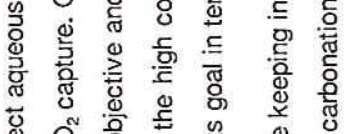

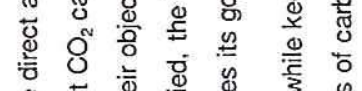

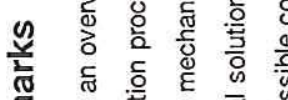

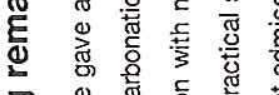

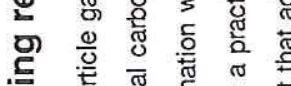

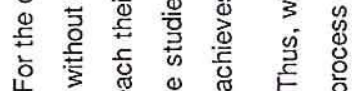

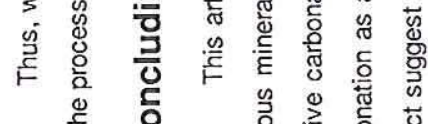

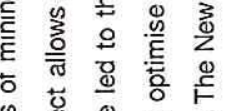

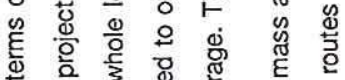

ᄃ

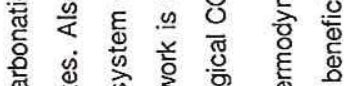

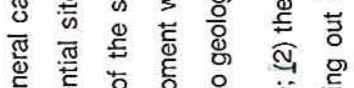

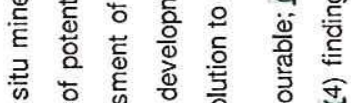

×

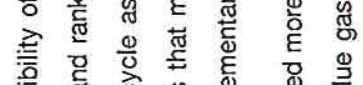

ฮั

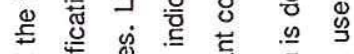

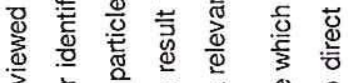

한

产 ए

号 胥

तิ

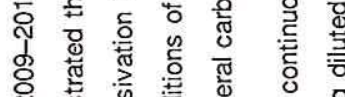

兽

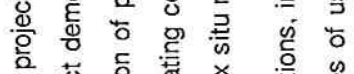

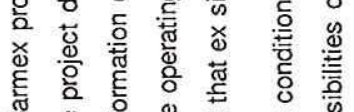

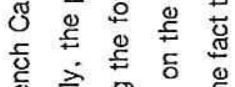

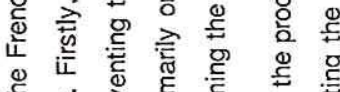

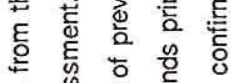

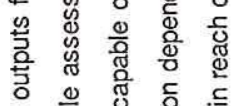

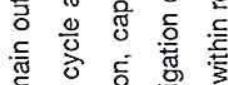

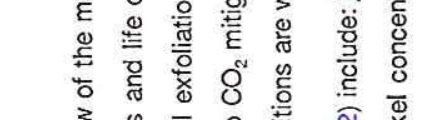

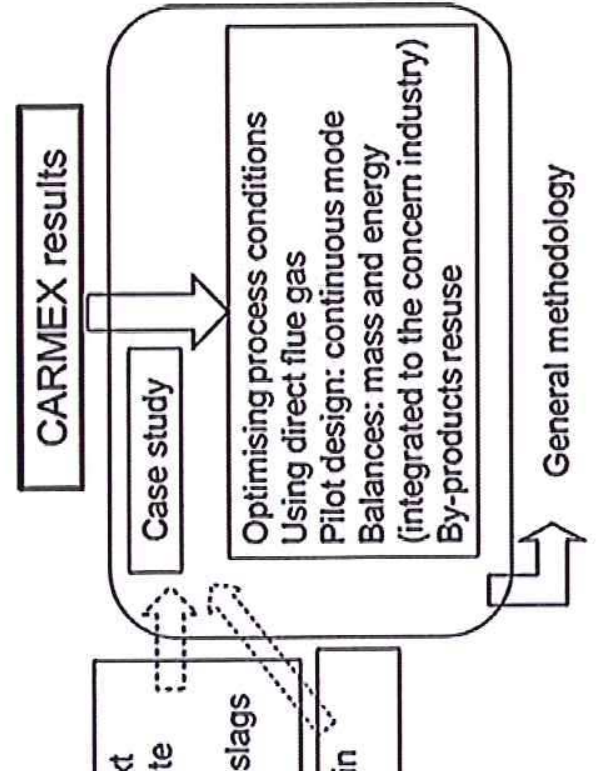

这芒

웡웡

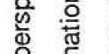

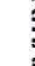

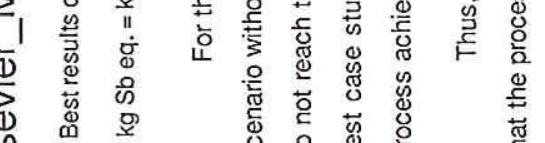

悹

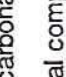


흠

. 


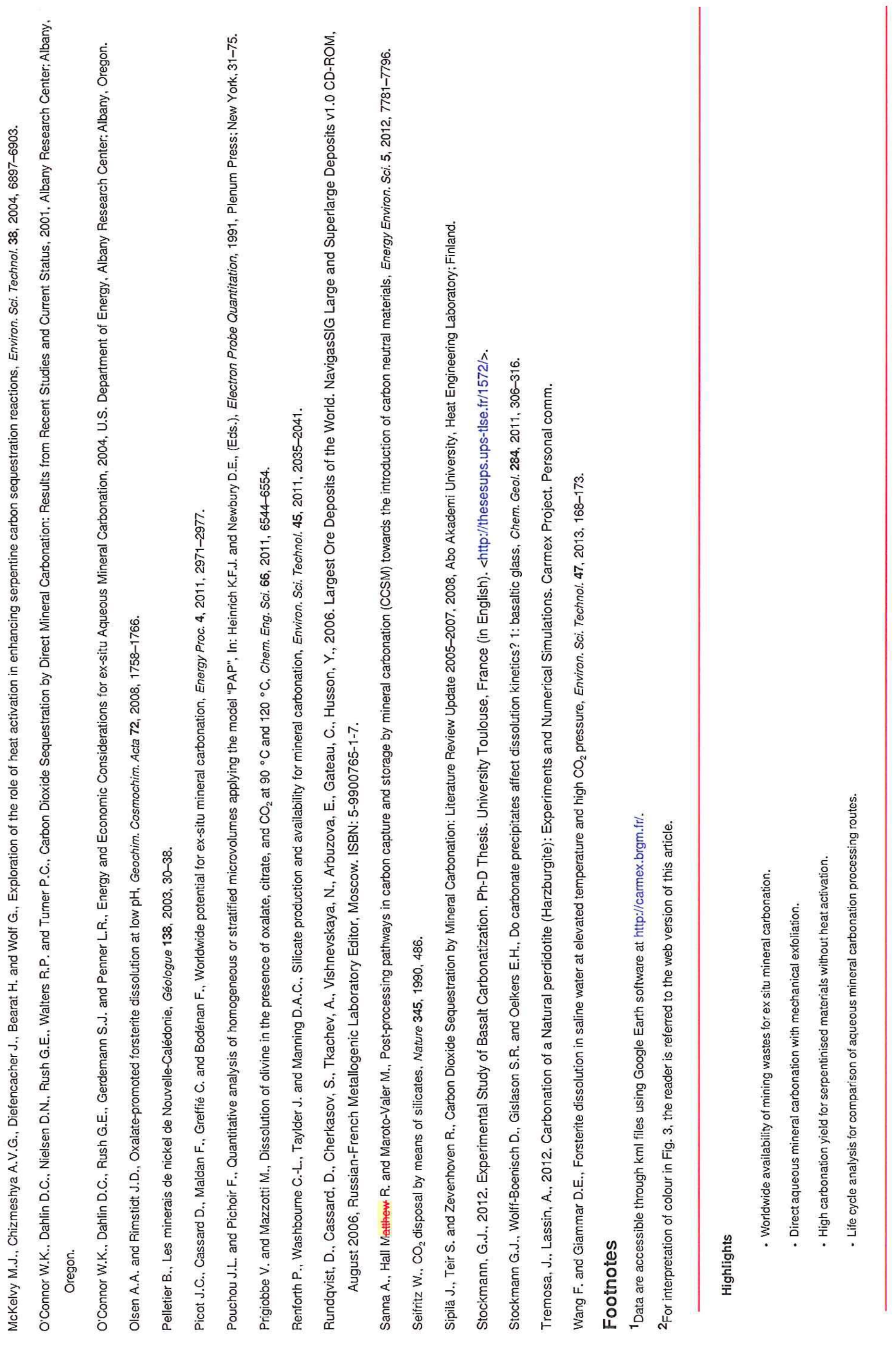

